\title{
Care and Counseling on Fetal Health Effects of Preconceptional Period Maternal Drug Use
}

\author{
Hediye Karakoç ${ }^{1 *}$ and Arzu Kul Uçtu ${ }^{2}$ \\ ${ }^{1}$ Department of Midwifery, KTO Karatay University, Turkey \\ ${ }^{2}$ Department of Midwifery, Bozok University, Turkey
}

Received: April 09, 2018; Published: April 17, 2018

*Corresponding author: Hediye Karakoç, PhD Student, Lecturer, Department of Midwifery, College of Health Science, KTO Karatay University, Konya, Turkey, Tel: (90) 541 2291726; Fax: 33220200 44; Email: hediye.bekmezci@hotmail.com

\begin{abstract}
Preconceptional care is a preventive health service that includes scanning, treatment and counseling services aiming to determine the physical, psychological and social factors that constitute a risk for the mother and fetus in the pre-pregnancy period and to improve the health. One of the primary goals of preconceptional care is the identification and maintenance of pre-pregnancy preventable risk factors to improve obstetric outcomes. The use of drugs containing teratogenic substances, which are among the risk factors that can be avoided, can cause adverse effects on the pregnant and embryo / fetus. In this study, it is aimed to investigate the effects of pre-pregnancy drug use on maternal and fetal health, care and counseling. Given the widespread use of medication and nutritional supplements among the women of reproductive age, the increased prevalence of chronic diseases, and the teratogenic effect of most medicines, it is necessary to provide a comprehensive framework for care and counseling services.
\end{abstract}

Keywords: Preconception Period; Pregnancy; Teratogen

\section{Introduction}

The embryonic period is an important period in which organs and systems begin to form rapidly, and can cause a variety of problems when subjected to adverse effects such as teratogenesis, infection and radiation [1]. Usually the embryonic period is completed in the first prenatal control and there are delays in taking care. Because many women are not aware of their pregnancy at this time [2,3]. For a healthy pregnancy, preconceptional care should be initiated [4]. For this reason, pre-conceptional period maintenance becomes important and counseling becomes necessary. Preconceptional care is a preventive health service that includes scanning, treatment and counseling services aiming to determine the physical, psychological and social factors that constitute a risk for mother and fetus in the pre-pregnancy period and improve health [5]. One of the primary goals of preconceptional care is the identification and reduction of preventable risk factors before pregnancy to improve obstetric outcomes [2,3]. The use of drugs containing teratogenic substances, which are among the risk factors that can be avoided, can cause adverse effects on the pregnant and embryo/fetus. In this study, it is aimed to investigate the teratogenic effects of maternal and fetal health on pre-pregnancy drug use, as well as the role of care and counseling services.

\section{Teratogenic Effect}

The term "teratogen" is used to describe an agent that can cause structural or functional abnormalities on the embryo/ fetus. Exposure to teratogens, physical and chemical properties of the agent, exposure pattern, gestational week, exposure to other agents, pregnancy and fetal biological susceptibility. Dose is a critical feature of teratogenic exposure. Teratogenic effects occur certain threshold level. Generally, the dose of drugs during pregnancy is the same as the dose used in nonpregnant adults. However, drugs thought to be safe during pregnancy may cause adverse effects if taken at high doses [6]. In addition, physiological changes during pregnancy can change the dosage of the drug effect. Physiological changes that may affect the pharmacokinetics and pharmacodynamic properties of drugs during pregnancy;

a. Changes in total body weight and body fat composition,

b. Changes in the bioavailability of drugs due to decreased stomach motility,

c. Increased plasma volume, extracellular fluid and total body water ratio, 
d. Increased cardiac output, stroke volume, heart rate and blood flow to the uterus, kidneys, skin, and mammals,

e. Decrease in plasma albumin concentration,

f. Increased glomerular filtration rate,

g. Changes in liver enzyme activity.

Table 1: Teratogenicity Summaries of Some Drugs.

\begin{tabular}{|c|c|}
\hline Drug & Effect \\
\hline Tetracyclines & $\begin{array}{l}\text { The Use of Drugs Such as doxycycline and Minocycline is Associated with Yellow-Brown Color } \\
\text { Change in the Milk Teeth. }\end{array}$ \\
\hline Sulfonamides & $\begin{array}{c}\text { Protein Enhances the Risk of Hyperbilirubinemia Near Birth By Taking up Bilirubin in the } \\
\text { Connective Part. }\end{array}$ \\
\hline Nitrofurantoin & $\begin{array}{l}\text { In women with G6PD Deficiency, Theoretically Increases the Risk of Hemolytic Anemia. G6PD } \\
\text { Deficiency is Contraindicated for the Risk of Potential Haemolysis in Infants of } 1 \text { Month Old. }\end{array}$ \\
\hline Quinolones & $\begin{array}{l}\text { Animal Studies Have been Associated with İrreversible Arthropathies and Cartilage Erosion; No } \\
\text { Teratogenic Effect was Found in Animal Studies. }\end{array}$ \\
\hline Metronidazole & It is not Teratogenic in the First Trimester Exposure. \\
\hline Warfarin & The Placental Barriers are Highly Teratogenic because they can pass easily. \\
\hline Heparin and Low Molecular Weight Heparins & $\begin{array}{l}\text { In Pregnancy the Anticoagulant is not Teratogenic Because of the Large Polar Molecules That do } \\
\text { not Cross the Teratogenic Placenta. }\end{array}$ \\
\hline Valproic Acid and Carbamazepine & During Embryogenesis, Spina Bifida and Neural Tube Defects are Associated with The Risk. \\
\hline Phenytoin & It can Lead to Abnormal Face Appearance. \\
\hline ACE İnhibitors & $\begin{array}{c}\text { The Use of Ace Inhibitors Causes many Anomalies Such as Growth Retardation, Limb Contractures } \\
\text { and Developmental Abnormalities. }\end{array}$ \\
\hline Diuretics & $\begin{array}{l}\text { The Use of Thiazide Diuretics Leads to Fetal Bleeding, Electrolyte imbalance and } \\
\text { Thrombocytopenia Soon After Birth. all diuretics can reduce breast milk production. }\end{array}$ \\
\hline Calcium Channel Blockers & It is Generally Considered Safe in Pregnancy. \\
\hline Methyldopa and Hydralazine & It is thought that it can be used Safely in Pregnancy \\
\hline Methotrexate & $\begin{array}{l}\text { It Affects Folic Acid Metabolism. High doses can lead to Developmental Retardation, Limb } \\
\text { Abnormalities, Rearward-Facing Ears, Micrognathia, and Hypoplastic Supraorbital Streaking. }\end{array}$ \\
\hline Androgens & $\begin{array}{l}\text { It is caused by complete Maskulization around } 7 \text { to } 12 \text { weeks. It causes Partial Masking in the } \\
\text { following Weeks. }\end{array}$ \\
\hline Lithium & It is Associated with an increase in Cardiovascular Malformation. \\
\hline Vitamin A & High doses are associated with Congenital Anomalies. \\
\hline
\end{tabular}

\section{Effect of Drug Use on Pregnancy Period}

Drug use during pregnancy has both maternal and fetal effects.

\section{Maternal Effects}

The drugs your mother uses can go through the placenta, directly affecting the fetus. Untreated chronic diseases can also negatively affect pregnancy outcomes [2]. Many women become pregnant despite problems such as asthma, epilepsy and hypertension, migraine, and diabetes that need to be treated [6]. Serious complications may be encountered if these diagnoses are not controlled. It is therefore important to determine the benefitloss ratio. However, there are few studies on drug pharmacokinetics during pregnancy. Little information is available about teratogenic risk or safety because pregnant women are often kept away from clinical trials. Animal studies do not provide sufficient evidence. Although much research has been done on hypertension, depression
It is necessary to constantly monitor the dosage and frequency of medication during pregnancy. Blood or serum concentrations of the drugs should be measured and monitored during pregnancy and appropriate dosage adjustments should be made when necessary. The risk, benefit balance of drug use should be assessed on the basis of individualized care. The following table describes the teratogenic effects of some drugs during pregnancy (Table 1). 
for pregnancy. Preconceptional care involves determining the conditions that need to be used in the pre-pregnancy period, and avoiding the use of unnecessary medications, management of the necessary treatments to optimize maternal health with the protection of the embryo and fetus at every stage of pregnancy, to minimize the exposure to drugs known to be harmful to the embryo or fetus [6]. It is a difficult process to decide whether to use drugs for pregnant women or women who plan to be pregnant. Individualized decision should be taken considering risk, benefit and treatment efficiency. In this process there are resources to help decide. Classification of drugs as "necessary" and "not necessary" in the preconceptional period will be beneficial. The necessary medicines should be used for the treatment of diseases that can cause serious morbidity [7].

All women in reproductive age should be scanned for teratogenic drug use and should be supervised for chronic diseases on pregnancy and the potential effects of drugs. In the preconceptional period, safer drugs should be used than teratogenic drugs. For women with chronic diseases, the minimum and the lowest dosages of essential drugs that control the disease should be used [7]. In the case of diseases such as diabetes, asthma, hypertension, thyroid diseases, sexually transmitted diseases including HIV, migraine, psychological disorders (depression, bipolar disorder), especially preconceptional counseling should be given. It may be necessary to stop the medication, reduce the dose, or take another step. For this reason, having information about the possible benefits and teratogenic effects of the drug has critical prescription [2]. Vitamins, minerals, plants, amino acids, enzymes, proteins, probiotics are accepted as nutritional supplements. Nutritional supplements are not regulated in the same way as prescription medicines. However, safety, efficiency, quality control, contamination, side effects and concerns about drug interactions have led to increased research.

While many health care professionals recommend certain nutritional supplements (folate, iron and calcium) during pregnancy and preconceptional period, the safety and effectiveness of many nutritional supplements (herbal and weight loss products) have not been proven. Most of the available data are based on case reports, animal studies and retrospective studies. Clinical trials evaluating the safety and efficiency of vitamin D, fish oil and herbal products during preconceptional and gestational periods are required. Midwives should advise women about dietary supplements, including medicinal herbs, weight loss products. High quality and prescription nutritional supplements should be encouraged [7]. The American College of Obstetricians and Gynecologists (ACOG) reports that history of drugs used or prescribed in the preconceptional period is required. ACOG also states that a doctor should be consulted before using any medication during pregnancy $[7,9]$. It is important for women planning to become pregnant to avoid unnecessary use of medication, and to inform the physician in case of diagnosis and treatment [7]. Midwives should educate women in reproductive age on the use of drugs in the period they plan to become pregnant.

\section{Result}

Given the widespread use of medicines and nutritional supplements among women in reproductive age, increased prevalence of chronic diseases, unknown teratogenic effects of most drugs, midwives should provide training and counseling especially for women planning to become pregnant. In general, the goals of drug use in preconceptional care $[6,7,10]$;

a) Health should be improved by moving away from cigarettes, alcohol, drugs and toxic substances in the prepregnancy period.

b) Women with chronic diseases should be counseled about treatment options and the effects of drugs. Preconceptional counseling should be provided to women who are in need to ensure that they make informed decisions.

c) Effective treatment of chronic diseases should be performed in the pre-pregnancy period.

d) All acute and chronic diseases should be followed during pregnancy.

e) Counseling should be provided to women to prevent the use of unnecessary medicines.

f) The use of drugs with a high teratogenic effect should be avoided when equally effective treatments which have lower risk such as warfarin (anticoagulant) and valproic acid (anticonvulsant) are available.

g) The least drug and the smallest dose that will effectively treat the maternal disease should be used without harming the health of the woman or the fetus.

\section{References}

1. Beji NK (2015) Women's health and diseases. Ankara: Nobel Medical Bookstores p. 209.

2. Steegers EAP (2005) Preconception care. Teratogenic risks of medication. International Congress Series 1279: 278-281.

3. Weerd SD, Steegers EAP (2002) The past and present practices and continuing controversies of preconception care. Community Genet 5: 50-60.

4. Frey KA (2002) Preconception care by the nonobstetrical provider. Mayo Clinic Proceedings 77: 469-473.

5. Baysoy NG, Özkan S (2012) Pre-pregnancy (preconceptional) care: People's health perspective. Gazi Medical Journal 23: 77-90.

6. Cragan JD, Friedman JM, Holmes LB, Uhl K, Green NS, et al. (2006) Ensuring the safe and effective use of medications during pregnancy: Planning and prevention through preconception care. Maternal and Child Health Journal 10(1): 129-135.

7. Dunlop AL, Jack B, Frey K (2007)National recommendations for preconception care: The essential role of the family physician. Journal of the American Board of Family Medicine 20(1): 81-84.

8. Schirm E, Meijer WM, Tobi H, Jong van den Berg LT (2004) Drug use by pregnant women and comparable non-pregnant women in The Netherlands with reference to the Australian classification system. European Journal of Obstetrics \& Gynecology and Reproductive Biology 114: 182-188. 
9. Coșkun A (2011) Preconceptional care and counseling: Place and importance in women's life. Journal of Nursing Education and Research 8(3): 8-15.

\section{(C) (i) This work is licensed under Creative} Submission Link: https://biomedres.us/submit-manuscript.php
10. Farahi N, Zolotor A (2014) Recommendations for preconception counseling and care. Indian Journal of Clinical Practice 24(11): 10061012 .

Assets of Publishing with us
$\begin{aligned} & \text { BIOMEDICAL } \\ & \text { RESEARCHES }\end{aligned}$
- Global archiving of articles
- Immediate, unrestricted online access

